DOI: $10.25100 /$ pfilosofica.v0i50.8716

\title{
PERPLEJIDADES DE LA DIGNIDAD HUMANA EN EL MARCO DE LOS DERECHOS HUMANOS
}

\author{
Concepción Delgado Parra \\ Universidad Autónoma de la Ciudad de México, México.
}

\begin{abstract}
Resumen
Este ensayo postula que la noción de dignidad humana formulada filosófica y moralmente desde la civilización occidental moderna, demanda hoy una re-lectura de sentido, a la luz de las perplejidades que anidan en la disonancia entre los principios morales y el derecho legal justiciable de los Derechos Humanos en las democracias contemporáneas. Si bien, la noción de Derechos Humanos deriva de la pertenencia a la familia humana en la que se asienta idealmente la universalidad de sus titulares y por el principio de autonomía, el resultado de esta mixtura tiene su traducción en dos concepciones problemáticas: una abstracta del ser humano sobre la que se instrumenta una supuesta universalidad que derivó en otra individualista que convierte a los hombres en sujetos aislados y egoístas. Identificar el núcleo de esta perplejidad en Platón, Aristóteles y Benhabib, constituye el propósito de esta reflexión.
\end{abstract}

Palabras clave: derechos humanos; dignidad humana; principios morales; derechos legales; libertad de acción.

Cómo citar este artículo: Delgado, C. (2020). Perplejidades de la dignidad humana en el marco de los derechos humanos. Praxis Filosófica, (50), 161-186. doi : 10.25100/pfilosofica.v0i50.8716.

Recibido: 4 de marzo de 2019. Aprobado: 6 de agosto de 2019. 


\title{
Perplexities of Human Dignity Within the Human Rights Framework
}

\section{Concepción Delgado Parra ${ }^{1}$}

\begin{abstract}
This essay postulates that the notion of human dignity formulated philosophically and morally in modern Western civilization now demands a re-interpretation of meaning in light of the perplexities that lie in the dissonance between moral principles and the triable legal right of Human Rights in contemporary democracies. Although the notion of Human Rights derives from belonging to the human family in which the universality of its holders is ideally based and on the basis of the principle of autonomy, the result of this mixture translates into two problematic conceptions: an abstract one concerning the human being, in which an alleged universality is orchestrated that led to another individualistic one that turns men into selfish, isolated subjects. Identifying the core of this perplexity in Plato, Aristotle and Benhabib is the purpose of this reflection.
\end{abstract}

Keywords: Human Rights; Human Dignity; Moral Principles; Legal Rights; Freedom of Action.

\footnotetext{
${ }^{1}$ Profesora-Investigadora de tiempo completo en el Posgrado de Humanidades y Ciencias Sociales de la Universidad Autónoma de la Ciudad de México. Postdoctorada por la Universidad de Yale (bajo la dirección de Seyla Benhabib). Integrante del Grupo de Investigación Teoría y Filosofía Política en la UACM. Proyecto de investigación en desarrollo: "Desafios de la integración social en las democracias". Ha publicado los siguientes libros: (2015), Los dilemas de la ciudadanía moderna para la realización de los derechos humanos: de Arendt a Benhabib. México: Editorial GEDISA-UACM; (2010), Violencias soterradas y el retorno de la alteridad radical. Ensayos sobre la comunidad por venir seguidos de la mano de Derrida, México: Luna de Barro; (2007), Una imposible vuelta a casa. Identidades nómadas y múltiples, México: UACM-Luna de Barro.
}

ORCID: 0000-0001-7388-4052 E-mail: concepcion.delgado@uacm.edu.mx 


\title{
PERPLEJIDADES DE LA DIGNIDAD HUMANA EN EL MARCO DE LOS DERECHOS HUMANOS
}

\author{
Concepción Delgado Parra
}

Universidad Autónoma de la Ciudad de México, México.

\section{Introducción}

La relevancia de la dignidad humana ${ }^{2}$ es innegable para la fundamentación de los Derechos Humanos (DDHH). Actualmente, existe un amplio consenso en virtud de que se trata de un valor inherente y absoluto a la persona derivado de su misma humanidad (Baertschi, 2005, pp. 19-21). La Declaración Universal de Derechos Humanos de 1948 resguarda en su Preámbulo "[...] el reconocimiento de la dignidad intrínseca y de los derechos iguales e inalienables de todos los miembros de la familia humana" (Peces-Barba, Fernández y Llamas, 2001, p. 283). Expresión que adquiere múltiples formas en las diferentes constituciones en el mundo, pero siempre enraizada en la naturaleza humana y la autonomía. Algunas veces aparece como valor estándar de un ejercicio fundacional; otras, asociada a intereses particulares (propiedad, protección en contra de la experimentación médica, etcétera); también, vinculada a ciertos sectores de la población (mujeres, indígenas, trabajadores o personas con discapacidad) (Daly, 2012, p. 14). La noción

${ }^{2}$ La noción de dignidad humana es un concepto con una larga historia que se extiende desde la Antigüedad hasta los debates y documentos ético-jurídicos contemporáneos. El discurso de Pico Della Mirandola Sobre la dignidad del hombre escrito en 1486, representa uno de los textos con el mayor número de reelaboraciones sobre el significado del concepto (Kateb, 2011, p. 4). En este sentido, el principio de la dignidad anclado a la humanidad no es una perrogativa de la época moderna (Berger, 1970, p. 342). Sin embargo, no es sino hasta finales del siglo XX que aparece el derecho a la dignidad (Daly, 2012, p. 14). 
emana, en primera instancia, de la pertenencia a la familia humana donde idealmente se asienta la universalidad de los titulares de dicha dignidad. Sin embargo, este proceso no es neutro, ya que está atravesado, en segunda instancia, por el principio de autonomía. El resultado de esta mixtura tiene su traducción en dos concepciones problemáticas: una abstracta del ser humano sobre la que se instrumenta una supuesta universalidad que derivó en otra individualista que convierte a los hombres en sujetos aislados y egoístas (Lucas, 1994, p. 44). La cuestión es que durante mucho tiempo la mayor parte de los seres humanos no han sido sujetos de derechos. Aunque en realidad, el problema no es que los derechos no hayan sido atribuidos universalmente a todos los hombres sino que "la mayor parte de los seres humanos no han sido considerados como tales" (Lucas, 1994, pp. 45-46).

La concepción de los DDHH, fundada en la tradición francesa de la Declaración de los Derechos del Hombre y del Ciudadano de 1789, nace de la mano con la historia del Estado de Derecho. Sin embargo, el concepto de dignidad humana deriva de diferentes vertientes en su formulación histórica. En la época pre-moderna, este valor estaba referido a la unión del hombre con Dios, haciendo del primero un excelente ser, creado a imagen y semejanza del segundo. Las cualidades que le fueron atribuidas a este hombre (pensamiento, lenguaje, entre otras), configuraron la idea de que el ser humano era capaz de expresar su grandeza y superioridad sobre los otros animales. En este sentido, fue considerado el único ser valioso puesto que Dios le había otorgado las capacidades más "nobles" para ejercer su predominio. Nobleza que pronto devino en un valor particular de la aristocracia. Dignidad y "nobleza" correrán de la mano durante siglos al amparo del cristianismo. El concepto de dignidad asumirá un contenido diferente en la época moderna. Se romperá el vínculo con lo divino y será resultado de la naturaleza humana. Al igual que en la época pre-moderna, estará atravesado por el elogio a las capacidades humanas, pero esta vez, interpretando al hombre como el sujeto en el que se encarna en su naturaleza el principio de dignidad. El antropocentrismo queda así preservado al insistir en la singularidad de la especie humana con respecto a otros animales. A esta reformulación se añade otra sustantiva: el hombre es un fin en sí mismo y como tal debe ser tratado, no como un medio. La forma que este imperativo kantiano toma en la época moderna se plasma en el ámbito jurídico con la aparición de los DDHH. A partir de este momento, la dignidad humana se edifica de manera vertical (superioridad de los seres humanos sobre los animales), pero también con alcance horizontal (igualdad entre los seres humanos). El sustento de esta articulación justifica el principio de igual dignidad, cuya idea constituye el fundamento del Estado de Derecho que considera a los individuos como ciudadanos con iguales 
derechos y obligaciones. Sin embargo, estos fundamentos serán cuestionados en la práctica. Por un lado, asumen que por su excelente naturaleza el ser humano tiene un valor absoluto y es merecedor de derechos. Y, por otro, esta obviedad se enfrenta a numerosas experiencias donde las personas han visto degradada y vulnerada su dignidad (Pelè, 2004, pp. 9-11).

La historia de los DDHH y del Estado de Derecho tienen su origen en el liberalismo político y se fundamentan sobre el principio de establecer límites al poder político. Lo problemático de los presupuestos de las teorías del derecho de corte liberal es que defienden la idea de que no todos los seres humanos son titulares de todos los derechos. El modo de operación de la autonomía y la razón en relación con los DDHH -que tienen su punto de partida en los derechos naturales- justifica que solamente los individuos autónomos son susceptibles de titularidad y capacidad para ejercer tales derechos. Aquellos que están imposibilitados para ejercer la autodeterminación o carecen de suficiencia económica o material se consideran dependientes, no autónomos, lo que justifica la negación de la titularidad de todos o algunos de los derechos o de la capacidad de ejercerlos. Esta manera de abordar los derechos humanos ignora que todos los seres humanos dependemos de una u otra manera de los demás. Al mismo tiempo, elabora una forma de interpretación del autogobierno basada en estereotipos asociados a ciertas clases de seres humanos que son situados como vulnerables o acreedores de cuidados. Al desconocer la inherente vulnerabilidad de los seres humanos en el proceso histórico de la configuración de los DDHH, éstos adquirieron su forma en el Derecho en términos de "derechos de la persona", lo que remite a una categoría jurídica, y no como derechos de los seres humanos (Barranco Avilés, 2016a, pp. 1-5). De este modo, la dignidad que en la época pre-moderna permaneció adosada a la aristocracia - a la "nobleza"-, y más tarde a la superioridad de "ciertos seres humanos", reconocidos como iguales frente a la ley, se traduce en la actualidad en que sólo los individuos autónomos son capaces de ejercer la autodeterminación y, por lo tanto, el acceso a su dignidad. La concepción tradicional sitúa a los DDHH en la dimensión normativa de la razón y la autonomía, de tal manera que las personas que históricamente fueron privadas de su libertad: pueblos colonizados, pueblos indígenas, mujeres, niños y niñas, pobres y dementes, solamente por mencionar algunos, eran consideradas indignas de ser titulares de derechos (Baxi, 2002, p. 29). La cuestión es que dicha práctica aún tiene validez para la interpretación jurídica del pensamiento occidental suscrito en la Declaración Universal de Derechos Humanos de 1948 (Barranco Avilés, 2016b). 
Pero, ¿cómo se dio el tránsito de la "familia humana" a la "autonomía de la persona"? ¿De la universalidad a la uniformidad y al desencarnado sujeto de derechos? ¿Cómo devino la dignidad en un valor adosado a los derechos humanos de unos pocos? Desde la perspectiva de Spaemann (1998, pp. 1516), la dignidad humana es un "concepto trascendental" que no indica de modo específico la fundamentación de lo que podría ser pensado como un "derecho humano". La frase "la dignidad del hombre es inviolable" tiene una doble acepción y, bajo esa lógica, conduce a diferentes interpretaciones. Se trata de un indicio sentado en un ámbito precedido por el dualismo del ser y del deber ser, vestigio que demanda la explicación de por qué tal concepto, más lejano que el de los derechos humanos se convierte en el siglo XXI en un elemento esencial del ordenamiento jurídico codificado (Pelè, 2010, p. 34). Inevitablemente, esta doble adscripción indica las ambigüedades de su cimentación en el presente.

Fundamentar y justificar la dignidad humana a partir de la humanidad ideal -compartida por todos los individuos- y la autonomía referida al principio kantiano soportado sobre la locución: "atrévete a servirte de tu propia razón" (Kant, 1991, p. 54) no garantiza el cumplimiento de los derechos humanos (Pfordten, 2009). Desde ese lugar, la noción deviene en una "tesis no interpretada". Según Werner Maihofer (2008, p. 5), su sentido tendría que revisarse a la luz del "horizonte espiritual" y "contexto histórico" que dio lugar a esta concepción jurídico-legal expresada en la civilización de Occidente. Desde la perspectiva de Jürgen Habermas (2010, p. 6), nos enfrentamos a la disyuntiva sobre si la dignidad humana es un concepto normativo fundamental sustantivo, del que los derechos humanos son derivados mediante la especificación de las condiciones en que son vulnerados, o si por el contrario, se trata de una expresión que proporciona una fórmula vacía sintetizada en un catálogo de derechos humanos individuales no relacionados entre sí3.

En este ensayo propongo rastrear la noción de dignidad referida a la naturaleza humana y al individuo en Platón y Aristóteles para mostrar los vestigios sobre los que se edifica la concepción abstracta y borrosa de la dignidad humana moderna que tomará forma sobre la base del imperativo

\footnotetext{
${ }^{3}$ Habermas recupera esta preocupación de la crítica de Hannah Arendt a la Declaración Universal de los Derechos Humanos, promulgada por la Asamblea General de Naciones Unidas en diciembre de 1948, plasmada en su breve texto The Rights of Man: What Are They? (Arendt, 1949, pp. 24-36), en el que afirma que en sus intentos por reformular los derechos humanos, ésta repite el espíritu y la actitud de las declaraciones tradicionales de finales del siglo XVIII, remarcando la confusión conceptual derivada de una visible "pérdida de realidad", toda vez que se trata del orden de un deber imposible de llevar a la acción.
} 
categórico kantiano que advierte, "obra de tal modo que uses la humanidad, tanto en tu persona como en la persona de cualquier otro y nunca solamente como un medio" (Kant, 2007, p. 42). Siguiendo la crítica de Schopenhauer, podría confirmarse que "la dignidad del hombre ha disimulado su incapacidad de proporcionar un fundamento real, o al menos plausible para la moral" (Schopenhauer, 1965, p. 89). Bajo este crisol, el imperativo categórico se convertiría en una mera ética de la intención (Scheler, 1941, p. 61-78). Desde este horizonte, abordaré la noción de dignidad en su correspondencia con la dialéctica de los modelos de naturaleza humana e individuo gestados en la obra de Platón y Aristóteles. La paradoja que anida en estos dos modelos radica en la forma que adquieren la autonomía y la razón. En el marco moral idealista de Platón, el hombre debe acceder al conocimiento verdadero usando su alma y despreciando su cuerpo, dejando un espacio limitado a la libertad del individuo humano. Y, en la concepción aristotélica no existe un valor inherente a la persona humana, pero sí una noción de individuo referida al valor de una conducta virtuosa que apunta hacia la autonomía máxima y la felicidad verdadera, derivando en una "vida buena" exclusiva y excluyente. La traducción que el pensamiento moderno llevó a cabo de estos dos modelos derivó en la falta de distinción entre los derechos humanos como "principios morales" y "derechos legales" que Seyla Benhabib discute en su controversia con Martha Nussbaum y Amartya Sen. Cuestión que desarrollaré en la última parte para mostrar que los modos en que la fundamentación y justificación de la dignidad construida a partir de la idea universal de la razón y la autonomía, entran en disonancia al poner en relación los reclamos morales con el derecho legal justiciable limitando la realización de los derechos humanos en las democracias contemporáneas.

\section{Dignidad como modelo de virtud vs. Igual dignidad entre los seres humanos (Platón)}

El contexto político-social y moral de la Antigüedad clásica aleja la idea de dignidad humana como fundamento de los DDHH. La igualdad no aparece en ningún momento como ideal de la organización social y política de la época y la concepción de individuo antiguo se distancia radicalmente de la definición moderna y contemporánea (Pelè, 2010). La división de clases, la concepción de ciudadano y la institución de la esclavitud, niegan sustantivamente la idea de "igual dignidad entre los seres humanos". En los ordenamientos jurídicos del mundo clásico, donde la esclavitud era reconocida como institución jurídica, el principio de respeto, como el de la democracia en las ciudades-estado, tenían valía desde el punto de vista jurídico-positivo únicamente para los hombres libres. "El mundo clásico 
parece por tanto justificar solamente un modelo de dignidad, el de la dignidad de la ciudadanía" (Pelè, 2010, p. 58). No obstante, cuando ensayamos reflexionar desde nuestro presente, desde nuestro contexto, la dignidad humana reclama tanto del ámbito inherente a la persona como de su igual dignidad de las personas. Estos dos significados no son equivalentes, pero guardan un vínculo sustantivo creado más tarde por la modernidad. En este sentido, abordar la dignidad en el mundo clásico podría considerarse un anacronismo, toda vez que el reconocimiento jurídico de la igualdad de la persona no constituye una preocupación de la época. Sin embargo, la preocupación de los pensadores griegos por girarse hacia un momento extremo de la razón, abre un camino para la ética del humanismo sobre la que se asentará la dignidad moderna, a pesar de que la conclusión no decante en la filosofía jurídico-política. Platón y Aristóteles no imaginaron ni remotamente postular la dignidad en términos de un principio con dimensión universal. En la Antigüedad solamente los estoicos -Epicteto, Séneca, Cicerón y Marco Aurelio- configuraron los atisbos de una idea universal de humanidad referida a la igualdad esencial de todos los hombres en cuanto a la dignidad que corresponde a cada uno (Recansens Siches, 2001, p. 549).

Hay, por tanto, que comenzar. Afirmar la idea de que la dignidad humana aparece en la filosofía clásica junto a la noción de individuo revela el comienzo de un "borramiento" de los límites entre lo universal y lo particular". Sería

\footnotetext{
${ }^{4}$ Hegel volverá a este "borramiento" de los límites entre lo universal y lo particular en la Fenomenología del espíritu para comprender la ruptura de la modernidad con el mundo antiguo. En el prefacio de esta obra, presentará la distinción entre la filosofía antigua preocupada por elaborar la dialéctica especulativa, en la que reconoce a Platón como el primero en elaborar una dialéctica que aspira a contemplar lo universal (Hegel, 2009, pp. 172-173) y a Aristóteles como el verdadero adoctrinador del género humano (Hegel, 2009, pp. 126-127), toda vez que es capaz de reducir las más diversas determinaciones a un solo concepto. De manera inversa, la tarea de la filosofía moderna consiste en realizar lo universal e "infundir espíritu" mediante la abolición de los pensamientos fijos y determinados (Hegel, 2009, pp. 132 y ss). En este sentido, la tarea aún pendiente radica en descubrir en esta universalidad, inmediatamente corroborada, la "pura certeza de sí mismo", la autoconciencia, cuyo "borramiento" constituye la deficiencia de la antigüedad (Gadamer, 2005, pp. 15-19). Ubicar a la dignidad humana en este "entremedio" es justo lo que permite la crítica a una noción que está prefigurada en el lugar de la tragedia, por estar adherida a una forma peculiar de fracaso. Una de las más importantes respuestas de Hegel en relación con la estructura de la tragedia en el encuentro con la conciencia es la confrontación entre la ley humana y la ley divina. Esta contradicción, cuya inscripción tendría que rastrearse en el juicio reflexivo en la comunidad ético-política contemporánea, particularmente en el debate desarrollado por Benhabib (2005; 1996; 1992), resulta del hecho de que ambas leyes prescriben derechos legítimos y necesarios para los agentes asignados a respetar tales leyes -en la Fenomenología, estarían referidas a Creonte y Antígona-, quienes estarían obligados por la razón y la costumbre a cumplir con sus deberes. Sin embargo, en la vida práctica estas dos leyes se
} 
imposible imaginar el ideal de autonomía y ciudadanía al margen de esta figura. "Más precisamente -dirá Pelè (2010, p. 703)-, el ideal de autonomía constituye uno de los rasgos que permite identificar al ser humano como individuo". En este sentido, el proceso de individualización edificado en la filosofía clásica constituye una piedra angular para comprender el tránsito del humanismo a la persona. No obstante, los portavoces de esta visión fueron los sofistas quienes apoyaban la emancipación de la jeunesse dorée ateniense. Se trataba de una clase que gastaba sus rentas en plena libertad, cuya extirpe no correspondía ni a la casta guerrera forjada en la disciplina espartana, ni tampoco a la casta sacerdotal configurada en torno a los viejos tabúes como sucedía en el cercano Oriente. Por primera vez se "razonó" en el doble sentido de la physis, generando una mezcla entre lo caprichoso-arbitrario y lo general-permanente, derivando en una mixtura entre "la ajuricidad y la exigencia del mismo Derecho para todos" (Bloch, 2011, p. 61). Para los sofistas, el derecho es goce y provecho y por esta razón a los poderosos les estaba todo permitido. Y, precisamente porque según la naturaleza todo es igual, introducen los derechos filantrópicos. Alcidamas alude a que la diferencia entre esclavos y libres es desconocida en la naturaleza. Hipias afirma que todos los hombres se encuentran en relación de conciudadanos y que todas las diferencias -incluida la desigualdad de la propiedad-son alojadas artificialmente por la ley. Protágoras enseñaba que el origen de la ley debía tener su base en una asamblea por lo que el Estado estaba obligado a conceder iguales derechos a todos. Sin embargo, aunque se introduce la idea de reunir a los hombres, no queda claro con qué objetivo se postula este principio en la Ilustración ateniense, "Lo único cierto es que la naturaleza, tanto como derecho del más fuerte que como igualdad de todos, estaba dirigida contra la tradición, es decir, contra la honestidad normada [...] Frente a todo ello, los sofistas subrayaron el valor del sujeto, de un sujeto individual-natural, libre e inteligente" (Bloch, 2011, p. 62).

Platón atacará permanentemente a los sofistas, sus premisas filosóficas esbozan una confianza en el hombre y perfilan un modelo de dignidad de la naturaleza humana plasmada en el campo intelectual en un marco moral idealista y dualista, en el que el hombre debe acceder al conocimiento verdadero usando su alma y despreciando su cuerpo. Desde este horizonte,

repelen, provocando que cada una de las partes defienda su ex-posición frente a la otra, en el marco de compromisos éticos que arriban en una suerte de conjetura especulativa imposible de reconciliar. Debatir sobre la decisión de transitar un camino de reflexión alternativo a la filosofía hegeliana para pensar la dignidad humana en los tiempos que corren constituye una tarea que rebasa el objetivo de este artículo. Sin embargo, estos argumentos constituyen un punto de partida para encuadrar el abordaje que se propone. 
postula la dignidad sólo si se contemplan las manifestaciones del alma humana que pretende alcanzar el Bien, purificándose de su corporeidad. Defiende una visión dualista del individuo, donde alma y cuerpo entran en un perpetuo conflicto. En el Fedón, este dualismo remite, incluso, al desprecio por la condición humana. Según Platón, la relación entre el cuerpo y lo humano es irracional, mortal y soluble; mientras que el alma es divina, inmortal y uniforme (Fedro III, 246a). Lo humano es asociado a los males que contaminan la grandeza del alma y ponen fin a su libertad (Fedro III, 256b). A pesar de esta reflexión que parece negar cualquier dignidad del ser humano, toda vez que define a los hombres a partir de sus finitudes y, particularmente, por su ignorancia inherente, retirándoles de toda facultad para comprender su realidad e individualidad (Fedro III, 250c; Melling, 1987, p. 106), existen elementos vinculantes con la dignidad humana moderna. En el Fedro, Platón distingue dos principios que arrojan al individuo tanto hacia el deseo natural como hacia la mejor sensatez: "[...] hay, en primer lugar, un conductor que guía un tronco de caballos y, después, estos caballos de los cuales uno es bueno y hermoso, y está hecho de esos mismos elementos. Y el otro de todo lo contrario, como también su origen. Necesariamente resultará difícil su duro manejo" (Fedro III, 246b). En la República referirá la lucha interna del hombre convertido en ocasiones en dueño de sí mismo y otras en esclavo de su persona (República IV, 431a). En las Leyes, define el significado del hombre como "juguete de Dios", reiterando la ausencia de libertad humana innata. No contempla ninguna autonomía inherente al ser humano ya que permanentemente se encuentra sometido por elementos que lo sujetan desde adentro (sus pasiones) y desde fuera (Dios) (Leyes III, 644d). Será, precisamente, cuando estos dos elementos encuentren su equilibrio, el momento en que el hombre podrá volverse digno. En este sentido, la dignidad del hombre en Platón se vincula a un objetivo específico: el conocimiento verdadero de las cosas. No es innata al hombre sino que ésta debe conseguirse, está reservada a una minoría de personas que gracias a ciertas predisposiciones y una educación adecuada, alcanzaría el Bien. De este modo, la dignidad del hombre no es mundanal ni es igual entre los individuos. Esta condición demanda en Platón un Estado ideal organizado a partir de la estricta división de clases con base en la jerarquía de las diferentes naturalezas humanas, defendiendo la idea de que algunos seres humanos son inferiores a otros.

El pensamiento de Platón deja poco espacio a la libertad de los individuos. Perfila una sociedad pre-totalitaria en la que no cabe de ningún modo el significado moderno de igual dignidad y cambia el fundamento 
de la división clasista de la sociedad dejando de tener un origen social para otorgarle uno natural:

Contempla un valor en el ser humano, pero no está igualmente distribuido entre todos los individuos [...]. La sociedad ideal encarna un estado donde la autonomía de cada uno se encuentra neutralizada - principio que será actualizado por Kant en términos de una idea "reguladora"-. Autonomía que intentará proteger e impulsar el significado moderno de la dignidad humana (Pelè, 2010, p. 88).

Esta idea corrobora la dificultad y el peligro de fundamentar la dignidad humana sobre la base de la naturaleza humana, como apunta Arendt (1968, pp. 296-298), en su crítica a los DDHH sustentados en la naturaleza del hombre, toda vez que excluye cualquier categoría de personas que no coinciden con la definición ética previa. En la obra de Platón nos encontramos frente a un Estado ubicado por encima de los hombres, omnipotente y capaz de corregir las imperfecciones de cada individuo (Platón, 1997b, p. 202). No obstante, se trata de un Estado dirigido a fomentar los lazos entre los hombres con una idea renovada de la política que persigue el Bien común. Esta configuración de la vida social irá acompañada de un énfasis en la autonomía individual, misma que se manifiesta en la razón y se plasma en el conocimiento del mundo (como autonomía externa) y en el conocimiento de sí mismo (como autonomía interna). Ámbitos que permitirán despertar la conciencia individual haciendo posible que el individuo sea capaz de conocerse a sí mismo y orientar su conducta hacia un ideal de virtud. En este trayecto, la virtud aparece como el fundamento de la dignidad individual y, en consecuencia, la autonomía del individuo lo convierte en el responsable de su propia conducta (Pelè, 2010, pp. 155-156).

Las contribuciones de la filosofía platónica a favor de la dignidad humana llevan a reflexionar sobre el individuo humano a partir de las especificidades de su naturaleza atribuidas a partir de un valor derivado de su particularidad y superioridad. La definición de hombre y su dignidad aparecerán enmarcadas estrictamente en un modelo de virtud, cuyo esquema niega la igual dignidad entre los seres humanos. Su concepto de dignidad humana se manifiesta a través de la individualización y la divinización de lo humano. Un modelo del ideal de la dignidad de la naturaleza humana aparecerá conectado al ideal político -sin soslayar que Platón recurre tanto a la persuasión como a la fuerza para organizar la sociedad ideal y concebir al ser humano- (Pelè, 2010, pp. 164-165). En este marco, el hombre se convierte en un "fin en sí mismo", toda vez que su valor está relacionado 
con la persona -definida como agente moral-. Por lo tanto, el individuo humano entrará en posesión de nuevas cualidades morales y racionales, de las que debe ser consciente, tanto para manifestar tales cualidades como para reconocer sus limitaciones. He aquí un doble movimiento expresado en la idea de dignidad humana del pensamiento platónico.

\section{Facultades humanas e individuales del ideal de "vida buena" en Aristóteles}

Aproximarse a la noción de dignidad humana en Aristóteles -al igual que en Platón-demanda reconocerla en un contexto en el que la organización social y política la vulnera. Sin embargo, su aporte está contenido en el modo en que elabora su antropología de un ser humano definido a partir de su individualidad. A diferencia de Platón, alma y cuerpo no se oponen sino que se complementan recíprocamente ${ }^{5}$. En el ser humano no existe necesidad de liberar el alma del cuerpo porque ambos, con sus respectivas funciones, configuran la integridad de su individualidad. La unidad de la naturaleza humana deviene justamente cuando el ser humano, definido como individuo, utiliza cuerpo y alma como herramientas para realizar su existencia mundanal (Acerca del alma II, 413b-413b). No hay tensiones entre la razón y el deseo, entre el alma humana y la voluntad, entre las pulsiones y el intelecto. El carro empujado por los tres caballos con un auriga que lucha por mantener el control se diluye y da paso a la configuración de un ser humano concertado por la voluntad, el deseo y la razón (Fortenbauch, 2002, p. 221). Será la función racional (y no el alma) la que confiera una esencia divina al ser humano, toda vez que el hombre es el que se compadece, aprende o discurre en virtud del alma (Acerca del alma I, 409a). Estas reflexiones matizan la naturaleza superior del alma y apuntan hacia la unicidad y protagonismo del ser humano. La expresión de esta racionalidad permite reconocer el valor inherente a la naturaleza humana. De donde se concluye que el hombre es un ser digno porque expresa una capacidad racional que utiliza el alma como herramienta, al mismo tiempo que el ser humano se individualiza desde una perspectiva externa, gracias a su naturaleza única (Pelè, 2010, p. 180).

En la filosofía de Aristóteles se esbozan las facultades humanas e individuales del ideal de "vida buena", que más tarde serán retomadas por el pensamiento moderno de la dignidad humana. En su Ética Nicomáquea

${ }^{5}$ Jean Paul Margot analiza una distinción sugerente en Aristóteles y Platón para advertir de las profundas implicaciones que tiene el paso de la división tripartita del alma -racional, irascible y concupiscible- a la división bipartita -racional e irracional- en sus consecuencias en el nuevo deseo de la vida moral (Margot, 2008, pp. 189-202). 
señala que existe un fin que deseamos por sí mismo, todas las cosas se quieren para alcanzarlo y se elige por él mismo nunca por otra cosa, "el bien es aquello hacia lo que todas las cosas tienden" (EN I, 1094a $3-4)$. Y, cuando se pregunta sobre el fin de la naturaleza humana constata que el fin es la felicidad (eudaimonía). El ser humano es el único capaz de perseguirla mientras que los otros animales, por naturaleza, son incapaces de buscarla (ENI, 1098b,1099b). Estas características de la felicidad perfilan un estado de perfecta autonomía, donde los fines y las funciones de la naturaleza humana se confunden y apoyan recíprocamente. La dificultad de la traducción del término eudaimonía - eu, designa algo "bueno" y daimon refiere a un genio o "espíritu guardián" - conduce a cierta ambigüedad en Aristóteles cuando lo remite "al hecho de estar bajo un genio propicio", dándole un sentido en términos de que el logro de la felicidad depende de un cierto coeficiente de buena suerte o de los dones especiales de la naturaleza individual (EUVIII, 1247a, 1248a, 1248b). Sin embargo, el pensamiento aristotélico rechaza que la felicidad dependa de la buena suerte. La idea de la "libertad interior" tiene su base en los rasgos señalados sobre el fin -asumido como felicidad-, cuya máxima implica la suficiencia del individuo, respecto a la fortuna y las circunstancias externas. Jaeger (1997, p. 456) relaciona esta "libertad interior" en Aristóteles con la "dignidad moral de la personalidad". En este sentido, la autonomía moral emerge dentro de las reflexiones aristotélicas sobre la felicidad individual, al tiempo que articula el valor del ser humano con el disfrute y logro de su autonomía asentando los cimientos de la dignidad humana moderna -no obstante, tal reconocimiento no implica la igual dignidad entre los individuos.

Aristóteles vincula estos dos rasgos a un tercero, cuya manifestación define la especificidad del ser humano y atributo fundamental de la dignidad de la naturaleza humana: el hombre visto en términos de "animal político". Con esta nueva característica defiende el valor intrínseco de lo político y descarta el valor meramente instrumental: "La razón por la cual el hombre es un ser social, [...], es evidente: [...] el hombre es el único animal que tiene palabra [...]. La palabra es para manifestar lo conveniente y lo perjudicial, así como lo justo y lo injusto". (Política I, 1252b - 10, 11, 12). El carácter político (o sociabilidad) inherente al ser humano, constituye una de las especificidades más importantes del individuo en Aristóteles. La posibilidad de la felicidad y una vida digna de ser vivida solo tiene cabida en el desarrollo de la naturaleza política del ser humano: "La felicidad y el 'vivir bien' se identifica con los rasgos de la naturaleza humana política en la realización de la máxima autonomía individual. Solamente en este espacio político, puede aparecer una 'vida buena' que proporciona eudaimonía” (Pelè, 2010, p. 194). 
Sin embargo, la "vida buena" en Aristóteles sólo puede ser disfrutada por una minoría de personas quienes, a su vez, se harán cargo de someter a las otras mediante diferentes técnicas de control que les permitan suponer que también gozan de una vida buena. Por lo tanto, la vida buena deviene en exclusiva y excluyente. En su concepción no existe un valor inherente a la persona humana, pero sí una noción de individuo referida al valor de una conducta virtuosa que apunta hacia la autonomía máxima y la felicidad verdadera. ¿Pero, qué sucede hoy en día con las personas que carecen de autonomía para llevar a cabo una vida digna? Tanto el pensamiento aristotélico como el discurso moderno coinciden en la existencia de una vida digna fundada en la razón y autonomía. El problema es que ambos se preocupan primero por el significado de la "vida buena" y utilizan la razón y la autonomía como criterios para evaluar la dignidad. La identificación de "vida buena" en Aristóteles le permite exaltar un modelo de vida sobre otras inferiores. Reconoce un modelo de vida conforme al hombre en el que muestra el camino para la manifestación de la razón y la autonomía, despreciando a quienes no son capaces de llevarla a cabo. La dignidad humana moderna percibe la "vida buena", no en el ideal de vida humana sino cuando muestra que la razón y la autonomía parecen frustradas. Y, en este proceso, pretende corregir las situaciones valorando al individuo como persona y no en función de los actos que realiza. De este modo, el encuentro entre Aristóteles y la dignidad humana se manifiesta en el concepto de "vida buena", pero en sentidos opuestos. En el primero, el hombre debe cambiar las circunstancias para demostrar su dignidad y, en la segunda, son las circunstancias las que deben modificarse para que el individuo sea capaz de expresar su dignidad (Pelè, 2010, pp. 269-270).

Como se puede apreciar, la dignidad humana que emerge del modelo platónico y aristotélico problematiza el contenido de la dignidad atribuida a la naturaleza humana y la forma que adquiere en el individuo. En el primer caso, se enfrenta a una fuerza vital que determina todo en un marco moral idealista en el que no existe a priori una libertad (de elección). Y, en el segundo, detenta la decisión de aceptar lo que sucede guiada por la búsqueda de la felicidad expresada en una vida buena. Aceptar (o no) esta fuerza suprema es la manifestación de la libertad del individuo humano. Así, pues, bajo la soberanía de este dilema gestado en la filosofía clásica se aperturan las perplejidades de la dignidad humana, cuya manifestación se expresa en la disonancia entre el principio moral -que demandaría de la libertad de la búsqueda de la felicidad expresada en la vida buena- y el derecho legal justiciable -como lugar de inscripción de la igualdad en la ejecución de la justicia, vigilante de la experiencia de la libertad para decidir. 


\section{Controversia Benhabib-Nussbaum: "principios morales" vs. "derechos legales"}

La problematización surgida de la filosofía clásica entre el reclamo moral y la forma legal de los DDHH derivan en lo que denomino las perplejidades del concepto de dignidad humana. La traducción que el pensamiento moderno llevó a cabo de estos dos modelos clásicos derivó en la falta de distinción entre los DDHH como "principios morales" y "derechos legales" que Seyla Benhabib ${ }^{6}$ discute en su controversia con Martha Nussbaum y Amartya Sen (Benhabib, 2011, pp. 77-93). A través de este debate abordaré los modos en que la fundamentación y justificación de la dignidad construida a partir de la idea universal de la naturaleza humana y autonomía entran en disonancia al poner en relación los principios morales con el derecho legal justiciable limitando la realización de los derechos humanos en las democracias contemporáneas (Benhabib, 2011, p. 79). Esta zona borrosa tiene su marca en la forma que adquieren la autonomía y la razón en la moral idealista de Platón, en la que el hombre accede al conocimiento verdadero usando su alma y despreciando su cuerpo, acotando el espacio de libertad al individuo humano. Y, en el marco aristotélico que impide realizar la No decisión, toda vez que no existe en él un valor inherente a la persona humana, pero sí una noción de individuo referida al valor de una conducta virtuosa que apunta hacia la autonomía máxima y la felicidad verdadera que lo lleva a buscar una vida buena que resulta exclusiva $-\mathrm{y}$ excluyente- por la inoperante concordancia entre un reclamo moral y su traducción al derecho legal.

En este escenario, la dignidad humana se configura como derecho legal, al remitir a un valor inherente y absoluto en el que anidan los derechos iguales e inalienables de todos los miembros de la familia humana. Sin embargo, la traducción que realiza el derecho legal dirigido a alcanzar la igualdad no necesariamente coincide con el principio moral (Cohen, 1996, p. 192). Para que la dignidad humana pierda su perplejidad, es necesario reconocer la distinción entre los derechos y reclamos morales. No basta con ejercer presión sobre las instituciones políticas y legislativas para llevar a cabo un principio moral a un derecho legal justiciable, ya que no todos los reclamos de derechos dan como resultado derechos legales específicos (Benhabib, 2011, p. 79).

\footnotetext{
${ }^{6}$ Seyla Benhabib es heredera de la tradición hegeliana y en su argumentación adquiere centralidad la resolución dialéctica de la ley particular con la ley universal. Su Universalismo interactivo es uno de los aportes más importantes reconocidos en el ámbito de la filosofía contemporánea (Delgado Parra, 2017a, pp. 112-123).
} 
Siguiendo la impronta de Benhabib, partiré de la idea de que existe un derecho moral fundamental, "el derecho a tener derechos" (Hannah Arendt) de todo ser humano a ser reconocido y, a su vez, reconocer a otros, como una persona con derecho a respeto moral y a derechos legalmente protegidos dentro de una comunidad humana. Lo que destaca en esta definición es la distinción entre los principios morales que protegen la libertad comunicativa de los individuos -cuya manifestación será el reclamo moral- y la positivación legal y de especificación de estos derechos. Esta conexión es necesaria y no meramente contingente. La dignidad adscrita a los derechos humanos en la mayoría de las constituciones en el mundo se coloca en la base de su defensa (Kateb, 2011, p. 4), toda vez que exige la presencia de un compromiso de las formas democráticas de gobierno, así como de una sociedad civil y una esfera pública libres (Benhabib, 2008, pp. 179-180). En este sentido, los procesos de aprendizaje, así como los enfrentamientos sobre el alcance y la justificación de los DDHH, no pueden ser de carácter global, como lo postula Nussbaum (1997; 2006), sino que corresponden a la especificidad cultural que los reclama; lo que sí es universal es la necesidad de su reconocimiento como principio legal. En esto radica el sentido político de la dignidad humana que, la mayoría de las veces queda diluida en la positivación de los derechos. Cuando el derecho de una persona a tener derechos se reconoce en un régimen constituido debidamente como Estado de Derecho, a través del reconocimiento de esa persona como miembro ${ }^{7}$, se reconoce el "principio de derecho"; pero esto deja abierta la pregunta sobre qué nivel de variación en la enumeración, contenido e interpretación de los derechos es permisible en diferentes "programas de derechos" (Donyets-Kedar, 2012, pp. 202-207). Muchas legislaturas, que podrían considerarse legítimas por estándares ampliamente compartidos de autorización democrática, transparencia y responsabilidad pública, proceden de un programa diferente de derechos (Benhabib, 2002). El problema que observa Benhabib, con respecto a la correspondencia que Nussbaum propone, uno a uno, entre una lista de derechos humanos derivada filosóficamente, basada en su teoría moral de las capacidades humanas, y las promulgaciones legales de legislaturas específicas ${ }^{8}$, es que descuida que

${ }^{7}$ Para Benhabib la membresía no es idéntica a la ciudadanía, esta última refiere a la forma más alta de membresía política en un sistema centrado en el estado-nación (Benhabib, 2011, pp. 111-116 у 232).

${ }^{8}$ Nussbaum presenta una lista de derechos humanos basada en capacidades centrales para que la vida esté a la altura de la dignidad humana: 1) Vida, como duración normal de la misma. 2) Salud física, buena salud. 3) Integridad física, poder desplazarse libremente, no sufrir ataques. 4) Sentidos, imaginación y pensamiento. 5) Emociones. 6) Razón práctica. 7) Afiliación y disponer de las bases sociales suficientes para sentir respeto por uno mismo. 
pueden surgir variaciones legítimas en la interpretación, contextualización y aplicación de los DDHH en las políticas de autogobierno. Benhabib indicará que se requieren reglas y procedimientos de traducción para hacer compatible la lista de capacidades humanas con la forma jurídica justiciable de los derechos humanos (Benhabib, 2011, p. 233).

Amartya Sen criticará también este intento de equivalencia que postula Nussbaum, por el hecho de que dicha "lista canónica", así como el peso que debe atribuirse a los diversos elementos no se pueden elegir sin una especificación adicional del contexto (Sen, 2004). Apunta que en este procedimiento lo que se muestra es una disminución sustancial del dominio del razonamiento público, dejando fuera la consideración de que los derechos humanos como demandas principalmente éticas se relacionan con la importancia de las libertades que constituyen el objeto de estos derechos (Sen, 2004, pp. 334). Si bien, Sen se abstiene de enumerar tales libertades, como Nussbaum lo hace con las capacidades, pone entre paréntesis la historia política de los derechos que siempre estuvieron estrechamente vinculados a los reclamos de legitimidad y gobierno justo (Benhabib, 2011, pp. 8081). Los derechos no se refieren simplemente a fuertes derechos morales que corresponden a los individuos; también son reclamos de justicia y legitimidad que enmarcan nuestra existencia colectiva. Cuando se pierde este horizonte, el contenido de la dignidad humana se invisibiliza o, por lo menos, se vuelve borroso.

No podemos solamente reducir los derechos al lenguaje de la corrección moral -dirá Benhabib-, violar un derecho es diferente a infligir un daño moral a una persona; ciertamente, algunas violaciones de derechos también son formas de daño moral. Por ejemplo, humillar a alguien frente a su familia, sus amigos y sus seres queridos inflinge un daño moral sobre su dignidad como persona; pero, en esta experiencia no se viola su derecho humano a la dignidad, como hubiera sucedido si se sometiera a la tortura y otras formas de castigo cruel e inusual. Todas las violaciones de los derechos humanos básicos, por el contrario, que inciden en la libertad comunicativa de la persona causan daños morales. Por lo tanto, si se le impide a alguien ejercer su capacidad para expresar su opinión libremente, no sólo se viola su derecho a la libertad de expresión, sino que también se daña su capacidad moral como persona capaz de comunicarse (Benhabib, 2004). Desde la perspectiva de Benhabib, ni Nussbaum, ni Sen, discuten esta distinción (necesaria) entre daño moral y violaciones a los derechos (Benhabib, 2011, p. 82).

8) Otras especies, como relación con el mundo natural próxima y respetuosa. 9) Juego, reír, y disfrutar. 10) Control sobre el propio entorno (Nussbaum, 2010, pp. 53-55). 
Sin embargo, la postura de Amartya Sen es más sensible a esta distinción, particularmente cuando sostiene que si los derechos son vistos como poderosos reclamos morales, es posible abrir rutas para promoverlos y realizarlos (Sen, 2009, pp. 364-365). En esta parte coincide Benhabib, aunque no deja de atribuir una confusión en cuanto a la lectura que Sen hace de los DDHH. Cuando éste escribe sobre "la importancia ética de la libertad de un tartamudo para no ser menospreciado o ridiculizado en las reuniones públicas" (Sen, 2009, p. 365) y la visibiliza como una demanda sin fuerza para ser tematizada por una legislación, al mismo tiempo que reconoce que debería ser protegida "a través de procesos educativos, de la discusión pública cívica y conducta social” (Sen, 2009, p. 366). Benhabib se pregunta sobre el tipo de derecho humano de la persona tartamuda que está siendo violado en este caso. Ciertamente, el derecho a no ser discriminado por una discapacidad y a no ser coaccionado y abusado debido a tal discapacidad. Pero, dirá Benhabib, ¿existe un "derecho humano" en contra de ser humillado en público a través de una burla o un ridículo? ¿No sería más apropiado nombrar a esto como un deber moral negativo, es decir, un deber de no violar la dignidad de otro ser humano sometiéndolo a falta de respeto y ridiculización? ¿En qué sentido hay un "derecho humano" para no ser humillado en público o privado? ¿No se trata de un deber moral que debemos a los demás de respetarlos? ¿Un deber moral que sólo puede traducirse al lenguaje de los DDHH cuando se produce alguna violación de la igualdad humana, dignidad o valor por parte de los jueces? El concepto de derechos humanos de Sen, definido como "reclamos éticos ligados constitutivamente con la importancia de la libertad humana", coloca entre paréntesis estas distinciones, al igual que lo hace Nussbaum con su lista de capacidades (Benhabib, 2011, p. 82).

La controversia Benhabib-Nussbaum coloca en el centro del debate al pensamiento liberal occidental, influido fuertemente por la tradición del contrato social que confunde la moral con el proyecto legal. Esta falta de distinción introduce una serie de características restrictivas, negativas y de mediación, que impiden la dignidad de la persona al estructurar un homo contractus sin interés real e inmediato en el bienestar de los demás. Se trata de un individuo egoísta, que ha refinado su auto-interés básico a partir de la justa reciprocidad, donde las partes son medidas por su habilidad para contribuir al pacto moral, de acuerdo con los principios de regulación. Esta debilidad del contractualismo moral constituye un terreno propicio para la fosilización de la dignidad al momento de ceñir la resolución por la reivindicación de los DDHH a su judialización. Enfocado hacia el principio de reciprocidad, el contractualismo moderno constituye un elemento natural 
de la ley, mismo que será trasladado al ámbito de la moral ${ }^{9}$. De esta forma, la comprensión de los problemas derivados de este desplazamiento queda circunscrita a los modos de la reciprocidad que adquiere la ley. El concepto de reciprocidad organiza los ejes de la ley y la idea legal de las tradiciones de Occidente. En este sentido, la ley es concebida como un dispositivo social para la regulación general de la conducta y la resolución de conflictos; opera dentro de un marco conflictivo de relaciones interpersonales; $y$, vinculada a las dos características anteriores, la centralidad de la ley se deposita sobre la necesidad de justificar las violaciones a la libertad personal (DonyetsKedar, 2012, pp. 206-207). Desde esta perspectiva, la ley es, especialmente, un instrumento regulador diseñado deliberadamente para lograr ciertos objetivos, a diferencia del pensamiento moral que sería pensado como "un fin en sí mismo", siguiendo la tradición kantiana. Bajo esta racionalidad, la ley se ha comprometido a pensar en patrones de polarización, en oposición a la moral que no exige ser confinada a una confrontación sobre la visión del mundo, de la vida buena. El discurso moral no necesita derivarse de una concepción de rivalidad entre las personas sino que podría basarse en un marco orientado hacia el otro y construido en términos de nuestra continuidad con las relaciones hacia los otros. Benhabib (2006, p. 38) asumirá este principio moral como una vía para la realización de la dignidad humana al plantear que cada individuo está situado en un espacio desde el que realiza el "habla", esto significa que se trata de una perspectiva parcial. Por ello, al asumir la acción de uno mismo a través de los ojos del otro, uno trasciende las limitaciones de la propia perspectiva, al ampliar la posición propia y, así, actuar moralmente (Benhabib, 1992). En este proceso se da un proceso un fenómeno de "reversión de la perspectiva", ante los miembros de una comunidad moral, cuando el juicio se articula desde la perspectiva de los otros. Tal reversibilidad es esencial para establecer los vínculos que nos unen como una comunidad humana. Nuestra capacidad para juzgar no significa emocionalmente asumir o aceptar el punto de vista del otro, sino simplemente tener presente que las perspectivas de los otros son posibles (Benbabib, 1992, p. 137). La moralidad no requiere centrar la legitimidad de sus demandas, en todo caso, tendría que ser explicada en términos de la justicia (Murphy, 2000). Considerar los requisitos morales para ser un buen amigo, un padre devoto, un socio responsable y digno de confianza, exige únicamente la demanda que supone (Williams, 2006).

Al trasladar el principio de reciprocidad de la ley a la moral mediante un argumento que confunde el proyecto de ley, con el proyecto moral, la

\footnotetext{
${ }^{9}$ Esta interpretación de la ley tiene su origen en la teoría de la constitución del Estado político contractualista planteada por Hobbes (1985).
} 
respuesta acerca de qué significa la "vida buena", se aborda a partir de un conjunto de reglas regulativas de coordinación, en las que los deberes morales hacia los otros quedan atrapados en un dispositivo de regulación de la conducta de la gente que opera dentro de un marco conflictivo de relaciones interpersonales, sostenido sobre la necesidad de justificar las violaciones a la libertad personal, bajo los principios de la reciprocidad, la cooperación y el voluntarismo (Delgado Parra, 2015, pp. 98-109). El uso de la ley como ideal normativo de la moralidad, introduce una serie de características restrictivas, negativas y de mediación poco exigentes, incluso potencialmente excluyentes para mantener a la moral como una guía suficientemente fuerte, para impulsar la dignidad de los derechos humanos. Su ética negativa diseña un tipo de "proceso ético" dirigido a la regulación de la moral y la vida social; apela a la mediación, porque considera que las relaciones éticas tienen lugar en una mesa de negociación; es poco exigente, debido a que piensa a la moralidad bajo el prisma de la legitimidad. Y, todo eso, como resultado de la confusión de la moral con el proyecto legal (Donyets-Kedar, 2012, p 226).

Desarticular esta traslación entre la ley y la moral, planteada por Benhabib, donde la acción política de un reclamo moral que demanda el reconocimiento de un derecho humano, primero, en la inscripción en su forma legal y, luego, en la aplicación de la justicia para alcanzar la "vida buena", no exclusiva sino incluyente e igualitaria, nos acerca a reconocer la dignidad humana en términos del significado que Hannah Arendt le otorga: libertad como accion que garantice un nuevo principio político y una nueva ley sobre la tierra. En la última parte del prefacio a la primera edición de Los origenes del totalitarismo, Arendt apunta:

[...] la dignidad humana necesita una nueva garantía fundada a partir de un nuevo principio político y una nueva ley sobre la tierra, cuya validez, esta vez, debe comprender a toda la humanidad, mientras que su poder debe ser limitado de manera estricta, enraizado y controlado por entidades territoriales definidas (Arendt, 1968, p. 9) [El énfasis y la traducción son míos].

Dos elementos se desprenden de esta afirmación, la necesidad de repensar la dignidad humana a partir de un nuevo principio político que garantice su realización y la validez de este principio basado en una ley que ponga en relación lo universal con lo particular ${ }^{10}$. En su crítica a los $\mathrm{DDHH}$ en el contexto de las experiencias de la Segunda guerra mundial, se

\footnotetext{
${ }^{10}$ Para profundizar en esta cuestión ver: "Sobre la comunidad ético-política contemporánea (Delgado Parra, 2014); Los dilemas de la ciudadanía moderna y la dignidad de los derechos
} 
pregunta por qué el concepto de derechos naturales e inalienables fallaron a la humanidad en el momento que más se necesitaban, a pesar de que éstos habían sido pronunciados un siglo y medio antes en Francia. A lo que responde diciendo que cuando el individuo carece de pertenencia a una comunidad política, sus derechos no son tan sagrados como el concepto de derechos individuales sugería (Arendt, 1968, p. 293). La facultad política simplemente es incapaz de realizarse en los desposeídos si estos no son reconocidos como miembros iguales de la humanidad (Benhabib, 2005, p. 50). Dos puntas de la misma madeja. Aparece la "tensión" entre la ley de lo universal y lo particular, la disonancia entre el derecho legal y el reclamo moral, como característica intrínseca de la unidad. Arendt identifica claramente la tensión entre estas dos dimensiones en el "derecho a tener derechos", de la que emerge su concepción de dignidad humana, pero también sabe que esta última debe prefigurar un movimiento que conduzca a la acción de la vida política, si de lo que se trata es de romper la aporía de los DDHH (Menke, Kaiser y Thiele, 2007, pp. 739-762).

Las tradiciones cristianas y las anti-filosófico políticas despojaron a la libertad del atributo de actuar (juntos) (Arendt, 2006, p. 163). A su pesar, esta concepción fue la que trasminó en el pensamiento de los filósofos modernos. Hobbes, Spinoza e incluso Kant, comprendieron la libertad fuera de la política (Hansen, 1993, p. 55). Este deslizamiento teórico llevó a la humanidad a la justificación de que los hombres tienen la capacidad para vivir legal y políticamente juntos, sólo cuando algunos tienen derecho a mandar y otros son forzados a obedecer (Arendt, 2006, p. 222). Para Arendt, la experiencia moderna del totalitarismo es resultado de este deslizamiento que condujo a la pérdida de la acción como principio de la vida política, traslación que el concepto de derechos humanos -naturales e inalienables-, fue incapaz de identificar y revertir. Y, es precisamente, en este intersticio donde Arendt vislumbra su concepción de dignidad humana (Michelman, 1996, p. 200).

El término de dignidad humana utilizado por Arendt se nutre de $-\mathrm{y}$ contra- Kant y Burke, al mismo tiempo que lo vincula a la política a través de Aristóteles. Convoca el sentido kantiano de que una actividad, o una forma de vida, tiene dignidad cuando es intrínsicamente valiosa y digna de ser llevada a cabo "para su propio beneficio"; propone la relación con la política a través del uso de Aristóteles, quien define a la política como un valor intrínseco al ser humano, diferenciándolo de otros animales sobre la base de que sólo él determina el curso de la vida a través de un 
proceso social de la política (Arendt, 2005, p. 53); y, finalmente, integra la concepción de Aristóteles de la comunidad política a los DDHH a través de Burke, quien considera que los únicos derechos que emanan del interior de la nación son los que gozan de reconocimiento (Helis, 2008, p. 74). Desde su planteamiento, los DDHH adquieren un carácter relativo o culturalmente específico y la dignidad humana -precedida de la libertad de acción que crea el espacio de aparición del hombre en el mundo-será la que otorgue el principio de universalidad. Cuando señala que los DDHH son particulares en cada cultura, es precisamente porque estos son objeto de debate y llevados a la vida en una comunidad política (Birmingham, 2006, p. 57). Sin embargo, la dignidad humana se mantiene como elemento universal ya que sólo ella es capaz de garantizar la participación en una comunidad política, toda vez que en su definición está contenida la condición de libertad de acción que impulsa y anima el inicio de toda acción humana.

El diálogo de Benhabib con el "derecho a tener derechos" de Arendt, donde la dignidad constituye el principio de acción política que deviene en principio universal, toda vez que deriva en la posibilidad de potenciar la realización de los DDHH, le permite afirmar que la interpretación de la ley y la moral apuntan hacia la necesidad de distinguir estos dos ámbitos que, si bien guardan una estrecha relación entre sí, supone un gran error leerlos de manera equivalente. Para Benhabib, la moralidad involucra valores tales como la justicia, la prosperidad humana, la dignidad. Estos discursos presuponen principios morales -en el sentido de que la justificación de los DDHH siempre hace referencia a los principios morales de las personas-. Fundamentalmente, los DDHH forman parte del vocabulario público de la justicia política, al designar una especial cercanía con los derechos morales (Benhabib, 2013, p. 42), lo que ha generado una interpretación equivocada en términos de su equivalencia. La importancia de distinguir estos dos proyectos, desde la perspectiva de Benhabib, consiste en que los DDHH solo pueden realizarse en el contexto de las relaciones sociales, por medio de los cuales nos tratamos unos a otros de acuerdo con los derechos de personalidad. Si partimos del supuesto de que la indignidad, asumida como rasgo que atraviesa permanentemente la vida de las personas, es incompatible con la acción política, tenemos que el desarrollo democrático deviene en un ejercicio imposible de realizar. El auto-gobierno, no solamente requiere de individuos libres sino también capaces de actuar con libertad; exige, además, no sólo que todos sean iguales, sino que disfruten de una "vida buena". Cuando las personas viven con indignidad o con el conocimiento de que para ejercer sus derechos se arriesgan a la indignidad, son incapaces de hacer efectivo el uso de la razón como vía de reivindicación de sus 
reclamos morales a la violación de los DDHH. Incluso, si se trata de ciudadanos "iguales entre sí", en derechos de participación formales y ante la ley, quienes sufren o corren el riesgo de la indignidad, no disfrutan de la integridad necesaria para el desarrollo de una verdadera autonomía racional. Las circunstancias humillantes se oponen a las acciones del "habla", de la "elección", del "juicio", exigidas a los ciudadanos que se autogobiernan.

Mediante la controversia con Nussbaum, Benhabib recupera el punto de vista de Arendt, al mismo tiempo que actualiza la dignidad derivada de los modelos de la naturaleza humana y del individuo de Platón y Aristóteles. Asume que la dignidad es un valor moral del ser humano que irrumpe a través de la acción política en el que se manifiesta la libertad en el individuo, cada vez que pone en relación el reclamo moral con el principio legal. Y, en este sentido, sitúa la libertad de acción como un valor inherente a la dignidad humana permitiendo que esta última se convierta en el nuevo principio político capaz de garantizar el "derecho a tener derechos", en el desarrollo de las democracias contemporáneas ${ }^{11}$.

\section{Referencias bibliográficas}

Arendt, H. (1949). The Rights of Man: What Are They? Modern Review, 3(1), 24-36.

Arendt, H. (1968). The Origins of Totalitarianism. Nueva York, EUA: Harcourt, Inc. Arendt, H. (2005). La condición humana. Barcelona, España: Paidós.

Arendt, H. (2006). Between Past an Future. Nueva York, EUA: Penguin Classics. Aristóteles [EN] [EU](1994a). Ética Nicomáquea. Ética Eudemia. Madrid, España:

Gredos.

Aristóteles. (1994b). Acerca del alma. Madrid, España: Gredos.

Aristóteles. (1988). Política. García Valdés, M. (trad.). Madrid, España: Gredos.

Baertschi, B. (2005). Enquête philosophique sur la dignité. Ginebra, Suiza: Les Editions Labors et Fides.

Barranco Avilés, M. C. (2016a). Vulnerabilidad, derechos y empresas. Cuadernos Electrónicos de Filosofía del Derecho, (34), 1-16. doi:10.7203/CEFD.34.8925. Barranco Avilés, M. C. (2016b). Condición humana y derechos humanos: algunas claves filosóficas para un modelo contemporáneo de derechos humanos. Madrid, España: Instituto de Derechos Humanos "Bartolomé de las Casas", UC3M-Dykinson.

Baxi, U. (2002). The Future of Human Rights. Oxford, EUA: Oxford University Press.

Benhabib, S. (1992). Situating the Self. Gender, Community and Postmodernism in Contemporary Ethics. Nueva York, EUA: Routledge.

${ }^{11}$ Esta idea hace resonancia con el planteamiento desarrollado por Marcelo Raffin (2018, pp. 195-211), en el que indaga la idea de los derechos humanos como un camino para potenciar la emancipación en las democracias contemporáneas. 
Benhabib, S. (1996). The Reluctant Modernismo of Hannah Arendt. Lanham, EUA: Rowman \& Littlefield Publishers, Inc.

Benhabib, S. (2002). The Claims of Culture. Equality and Diversity in the Global Era. Princeton, EUA: Princeton University Press.

Benhabib, S. (2004). The Rights of Others. Aliens, Residents and Citizens. Cambridge, Inglaterra: Cambridge University Press.

Benhabib, S. (2005). Los derechos de los otros. Extranjeros, residentes y ciudadanos. Barcelona, España: Gedisa.

Benhabib, S. (2006). Another Cosmopolitanism. Nueva York, EUA: Oxford University Press.

Benhabib, S. (2008). Otro universalismo: Sobre la unidad y diversidad de los derechos humanos. Isegoria. Revista de Filosofia Moral y Política, 39, 175-203, doi: 10.3989/isegoria.2008.i39.627.

Benhabib, S. (2011). Dignity and Adversity. Human Rights in Troubled Times. Cambridge, Inglaterra: Polity Press.

Benhabib, S. (2013). Reason-Giving and Rights-Bearing: Constructing the Subject of Rights. Constellations, 20(1), 37-50. doi: 10.1111/cons.12027.

Berger, P. (1970). On the Obsolescence of the Concept of Honor. Archives Européenes de Sociologie, XI(2), 339-347.

Birmingham, P. (2006). Hannah Arendt and Human Rights: The Predicament of Common Responsability. Indianapolis, EUA: Indiana University Press.

Bloch, E. (2011). Derecho natural y Dignidad humana. Madrid, España: Clásicos Dykinson.

Cohen, J. L. (1996). Rights, Citizenship and the Modern Form of the Social: Dilemmas of Arendtian Republicanism. Constellations, 3(2), 164-189. doi: 10.1111/j.1467-8675.1996.tb00052.x.

Daly, E. (2012). Dignity Rights. Courts, Constitutions, and the Worth of the Human Person. Filadelfia, EUA: University of Pennsylvania Press.

Delgado Parra, C. (2014). Sobre la comunidad ético-política. Andamios, 11(24), 15-33.

Delgado Parra, C. (2015). Los dilemas de la ciudadanía moderna y la dignidad de los derechos humanos. De Arendt a Benhabib. Ciudad de México, México: UACM-Gedisa.

Delgado Parra, C. (2017b). El concepto de libertad en Hannah Arendt para el ejercicio de los derechos humanos. Tla-Melaua. Revista de Ciencias Sociales, 10(41), 6-25.

Delgado Parra, C. (2017a). Hospitalidad y ciudadanía desde la perspectiva de Seyla Benhabib. En E. Conde, M. Oliva y R. Rodríguez. (Comps.), Hospitalidad y ciudadanía. De Platón a Benhabib (pp. 105-136). Ciudad de México, México: Universidad Autónoma de la Ciudad de México-Ítaca.

Donyets-Kedar, R. (2012). Reciprocity in Morality and Law. Law and Ethics of Human Rights, 6(2), 202-227. doi: 10.1515/1938-2545.1073.

Fortenbauch, W. (2002). Aristotle on Emotion. Londres, Inglaterra: Duckworth. 
Gadamer, H. (2005). La dialéctica de Hegel. Cinco ensayos hermenéuticos. Madrid, España: Cátedra Teorema.

Habermas, J. (2010). El concepto de dignidad humana y la utopía realista de los derechos humanos. Diánoia, LV(64), 3-25. doi: 10.21898/dia.v55i64.218.

Hansen, P. (1993). Hannah Arendt: Politics, History and Citizenship. Stanford, EUA: Stanford University Press.

Hegel, G. W. F. (2009). Fenomenología del espiritu. Valencia, España: Pre-Textos. Helis, J. (2008). Hannah Arendt and Human Dignity: Theoretical Foundations and Constitutional Protection of Human Rights. Journal of Politics and Law, 1(3), 73-78. doi: 10.5539/jpl.v1n3p73.

Hobbes, T. (1985). Leviathan. Indianapolis, EUA: Hackett Pub. Co.

Jaeger, W. (1997). Aristóteles. Bases para la historia de su desarrollo intelectual. Ciudad de México, México: FCE.

Kant, I. (1991). An answer to the question" what is Enlightenment? En H. S. Reiss. (Ed.), Kant Political Writings (pp. 54-60). Cambridge, EUA: Cambridge University Press.

Kant, I. (2007). Fundamentación de la metafisica de las costumbres. San Juan, Puerto Rico: Pedro M. Rosario Barbosa.

Kateb, G. (2011). Human Dignity. Cambridge, EUA: The Belknap Press.

Lucas, J. (Ed.). (1994). El desafio de las fronteras. Derechos humanos y xenofobia frente a una sociedad plural. Madrid, España: Temas de Hoy.

Maihofer, W. (2008). Estado de Derecho y dignidad humana. Buenos Aires, Argentina: Editorial "B de F".

Margot, J. P. (2008). Aristóteles: deseo y acción moral. Praxis Filosófica, (26), 189-202. doi: 10.25100/pfilosofica.v0i26.3307.

Melling, D. J. (1987). Introducción a Platón. Madrid, España: Alianza.

Menke, C., Kaiser, B., y Thiele K. (2007). The "Aporias of Human Rights" and the "One Human Right". Regarding the Coherence of Hannah Arendt's Argument. Social Research, 74(3), 739-762.

Michelman, F. I. (1996). Parsing “A Right to Have Rights". Constellations, 3(2), 200-208. doi: 10.1111/j.1467-8675.1996.tb00054.x.

Murphy, L. B. (2000). La paradoja democrática. Barcelona, España: Gedisa.

Nussbaum, M. (1997). Capabilities and Human Rights. Fordham Law Review, 66(273), 273-300. Recuperado de http://ir.lawnet.fordham.edu/flr/vol66/iss2/2.

Nussbaum, M. (2006). Frontiers of Justice: Disability, Nationality, Species Membership. Cambridge, EUA: The Belknap Press of Harvard University Press.

Nussbaum, M. (2010). Crear capacidades. Propuesta para el desarrollo humano. Barcelona, España: Paidós.

Peces-Barba, G., Fernández, C., y Llamas, A. (2001). Textos básicos de derechos humanos. Madrid, España: Arazandi.

Pelè, A. (2004). Una aproximación al concepto de dignidad humana. Universitas: Revista de Filosofía, Derecho y Política, (1), 9-13.

Pelè, A. (2010). La dignidad humana. Sus orígenes en el pensamiento clásico. Madrid, España: Dykinson. 
Platón. (1987). Diálogos (VIII-Leyes). Madrid, España: Gredos.

Platón. (1997a). Diálogos (III-Fedro-Fedón). Madrid, España: Gredos.

Platón. (1997b). Diálogos (IV-República). Madrid, España: Gredos.

Pfordten, D. (2009). On the Dignity of Man in Kant. Philosophy, 84(3), 371-391. doi: $10.1017 / \mathrm{S} 0031819109000370$.

Raffin, M. (2018). Droits humains et émancipation: Un outil pour la démocratie ? Une analyse de la potentialité des droits à partir de la pensée foucaldienne. Praxis Filosófica, (47), 195-211. doi: 10.25100/pfilosofica.v0i47.6614.

Recansens Siches, L. (2001). Tratado General de Filosofia del Derecho. Ciudad de México, México: Porrúa.

Scheler, M. (1941). Ética. Revista de Occidente, 1(3), 61-78.

Sen, A. (2004). Elements of a Theory of Human Rights. Philosophy and Public Affairs, 32(4), 315-356. doi: 10.1111/j.1088-4963.2004.00017.x.

Sen, A. (2009). The Idea of Justice. Cambridge, EUA: The Belknap Press of Harvard University Press.

Schopenhauer, A. (1965). Los dos fundamentos de la ética (Vol. II). Buenos Aires, Argentina: Aguilar.

Spaemann, R. (1998). Sobre el concepto de dignidad humana. En M. Correas, et al (Edits.), El derecho a la vida. Pamplona, España: Ediciones Universidad de Navarra.

Williams, B. (2006). Ethics and Limits of Philosophy. Abingdon, EUA: Routledge. 